Fixed Point Theory, 20(2019), No. 2, 729-740

DOI: $10.24193 /$ fpt-ro.2019.2.48

http://www.math.ubbcluj.ro/ nodeacj/sfptcj.html

\title{
ALTERNATIVE CHARACTERIZATIONS OF AGIFSs HAVING ATTRACTOR
}

\author{
SILVIU-AURELIAN URZICEANU
}

\author{
Faculty of Mathematics and Computer Science, University of Piteşti \\ Târgul din Vale 1, 110040, Piteşti, Argeş, Romania \\ E-mail: fmi_silviu@yahoo.com
}

\begin{abstract}
In this paper we study affine generalized iterated function systems (for short AGIFSs) which are particular cases of the concept of generalized iterated function system introduced by R. Miculescu and A. Mihail. Using a technique introduced by F. Strobin and J. Swaczyna, we associate to each $n \in \mathbb{N}^{*}$ and each AGIFS $\mathcal{F}$ a new AGIFS $\mathcal{F}_{n}$. Our main result states that the following statements are equivalent: a) $\mathcal{F}$ has attractor. b) There exists $n \in \mathbb{N}^{*}$ such that $\mathcal{F}_{n}$ has attractor. c) There exists $n \in \mathbb{N}^{*}$ such that $\mathcal{F}_{n}$ is hyperbolic. d) There exists $n \in \mathbb{N}^{*}$ such that $\mathcal{F}_{n}$ is topologically contractive.

Key Words and Phrases: Affine generalized iterated function system (AGIFS), attractor, hyperbolic AGIFS, topologically contractive AGIFS.
\end{abstract}

2010 Mathematics Subject Classification: 28A80, 54H20.

Acknowledgements. I want to thank the referee whose remarks and comments lead to improvement of the paper.

\section{REFERENCES}

[1] R. Atkins, M. Barnsley, A. Vince, D. Wilson, A characterization of hyperbolic affine iterated function systems, Topology Proc., 36(2010), 189-211.

[2] P. Jaros, L. Maślanka, F. Strobin, Algorithms generating images of attractors of generalized iterated function systems, Numer. Algorithms, 73(2016), 477-499.

[3] A. Kameyama, Distances on topological self-similar sets and the kneading determinants, J. Math. Kyoto Univ., 40(2000), 603-674.

[4] R. Miculescu, Generalized iterated function systems with place dependent probabilities, Acta Appl. Math., 130(2014), 135-150.

[5] R. Miculescu, A. Mihail, Alternative characterization of hyperbolic affine infinite iterated function systems, J. Math. Anal. Appl., 407(2013), 56-68.

[6] R. Miculescu, A. Mihail, On a question of A. Kameyama concerning self-similar metrics, J. Math. Anal. Appl., 422(2015), 265-271.

[7] A. Mihail, R. Miculescu, A generalization of the Hutchinson measure, Mediterr. J. Math., 6(2009), 203-213.

[8] A. Mihail, R. Miculescu, Applications of fixed point theorems in the theory of generalized IFS, Fixed Point Theory Appl., Vol. 2008, Art. ID 312876, 11 pp.

[9] A. Mihail, R. Miculescu, Generalized IFSs on noncompact spaces, Fixed Point Theory Appl., Vol. 2010, Art. ID 584215, 11 pp. 
[10] N. Secelean, Generalized iterated function systems on the space $l^{\infty}(X)$, J. Math. Anal. Appl., 410(2014), 847-858.

[11] N. Secelean, Invariant measure associated with a generalized countable iterated function system, Mediterr. J. Math., 11(2014), 361-372.

[12] F. Strobin, Attractors of generalized IFSs that are not attractors of IFSs, J. Math. Anal. Appl., 422(2015), 99-108.

[13] F. Strobin, J. Swaczyna, On a certain generalisation of the iterated function system, Bull. Aust. Math. Soc., 87(2013), 37-54.

[14] F. Strobin, J. Swaczyna, A code space for a generalized IFS, Fixed Point Theory, 17(2016), 477-493.

Received: February 21, 2017; Accepted: July 5, 2017. 
